\title{
Q Fever Endocarditis: A Diagnostic Challenge
}

Rebecca Jeffery, Steve Walsh, Babar Haroon

DOI: 10.22374 /cjgim.v13i1.218

\section{About the Authors}

Rebecca Jeffery is with the Department of Family Medicine, McMaster University, Hamilton, ON. Babar Haroon and Steve Walsh are with the Faculty of Medicine, Dalhousie University, Halifax, NS. Babar Haroon is with the Department of Medicine and the Department of Critical Care, Dalhousie University, Halifax, NS.

Correspondence may be directed to: rjeffer4@gmail.com

Submitted: June 16, 2017. Accepted: July 27, 2017. Published: March 5, 2018.

\begin{abstract}
Q fever is a zoonotic disease, typically spread by aerosol transmission from infected animals to humans. It can present with a variety of clinical manifestations, but endocarditis is the most common manifestation. We present a case of an 80-year-old man with a prior bioprosthetic aortic valve (AV) replacement who presented with chronic constitutional symptoms that acutely worsened over two days leading up to his presentation. An initial echocardiogram was equivocal for endocarditis, and bloodwork revealed a bicyotpenia, elevated ferritin, and negative blood cultures. He was diagnosed with $\mathrm{Q}$ fever endocarditis after positive serology for Coxiella burnetti. Treatment for this patient involved a 24-month course of doxycycline and hydroxychloroquine.
\end{abstract}

\section{Résumé}

La fièvre Q est une zoonose, dont la transmission se fait généralement par voie aérosol d’un animal infecté à l'humain. Les manifestations cliniques sont variées, mais l'endocardite en est la plus courante. Nous présentons le cas d'un homme de 80 ans qui a dans le passé subi une chirurgie de remplacement de la valve aortique (VA) par une bioprothèse. Il présente des symptômes constitutionnels chroniques qui se sont vivement aggravés dans les deux jours précédant la consultation. Un premier échocardiogramme indique de manière équivoque des signes d'endocardite et une analyse sanguine révèle une bicytopénie, un taux élevé de ferritine et des hémocultures négatives. À la suite d'une sérologie positive à Coxiella burnetti, on lui diagnostique une endocardite de la fièvre $Q$. Le traitement de ce patient a nécessité l'administration de doxycycline et d'hydroxychloroquine sur une période de 24 mois.

\section{Case Presentation}

An 80-year-old male with a prior bioprosthetic aortic valve (AV) replacement presented to the emergency department (ED) with a 2-year history of fatigue, malaise and constitutional symptoms including fevers, night sweats, and 5-10 pounds of weight loss. He previously had Streptococcus mitis native valve endocarditis in the setting of a dental abscess. He was on no medications and denied illicit drug use. He had presented to his family physician on multiple occasions over the previous year: routine screening bloodwork was established, and Lyme serology testing was negative. Six months prior to this presentation, he was evaluated by Cardiology, during which he did not have signs or symptoms of congestive heart failure. A transthoracic echocardiogram (TTE) revealed a normal bioprosthetic aortic valve (AV), with normal functional indices and no vegetations, and blood cultures were negative. He returned to his family doctor three weeks prior to ED presentation with complaints of worsening lassitude and was treated with oral antibiotics for community acquired pneumonia. 
He presented to his local ED with a 48-hour history of profound weakness (difficulty ambulating and a fall at home), fevers, chills, rigors, and back pain. He denied dyspnea, cough, chest pain, sputum production, painful joints, rashes, or urinary/ gastrointestinal symptoms. In the ED he was febrile, tachycardic, and hypotensive. An initial work-up including blood and urine cultures was done, and a chest radiograph was normal. He was treated with ertapenem, followed by piperacillin-tazobactam and admitted to hospital. A TTE was done on day 4 of his admission and demonstrated a non-specific echodensity on the $\mathrm{AV}$, consistent with a vegetation. His antibiotic treatment was changed to ceftriaxone and vancomycin. All cultures remained negative. He was then transferred to a tertiary care hospital for ongoing care.

Another set of blood cultures was drawn, and antibiotics were continued. The TTE was reviewed and determined not to be consistent with a prosthetic valve endocarditis (PVE) and the Infectious Disease Service was consulted. On further inquiry, it was noted that he had two indoor, non-pregnant cats; he lived on a farm but had no livestock; and he spent much of his time in the woods. He denied recent travel, intravenous drug use, or high-risk sexual activity. Immunizations were up to date. On physical examination, he had mild splenomegaly and tenderness over the second lumbar (L2) vertebra on palpation. His examination was otherwise normal: in particular, heart sounds were normal, and he had no lymphadenopathy. Review of microbiology from the referral centre showed six sets of negative blood cultures and one negative urine culture. His blood cell count revealed a progressive bicytopenia with leukopenia and thrombocytopenia, with normal reticulocyte count and elevated ferritin. Lyme serology, hemochromatosis screen, and vasculitis panel were all negative. His serum protein electrophoresis showed a beta-gamma bridge, and C-reactive protein and erythrocyte sedimentation rate were mildly elevated. A urinalysis showed hematuria and trace protein, but was negative for leukocytes or nitrites. A magnetic resonance imaging scan was done to investigate ongoing back pain showed compression fracture of the L2 vertebra, suggestive of recent injury, but there was no evidence of tumour or discitis.

Further bloodwork included serology for human immunodeficiency virus, hepatitis $\mathrm{C}$ virus, Bartonella, Coxiella, and Mycobacterium culture. A peripheral blood smear showed anemia and spherocytes, suggestive of an autoimmune hemolytic process. Hematology was consulted. A bone marrow biopsy was done to rule out myelodysplastic syndrome, and a sample was sent for cultures and acid fast bacilli stain. The marrow was slightly hypercellular with adequate hematopoiesis: there was no evidence of myeloma or lymphoma. Ring sideroblasts were present and were thought to be reactive in nature.
Coxiella burnetti serology returned strongly positive, with phase I IgG 1:16384, phase II IgG 1:65536, and phase I IgM $<1: 16$. The patient began oral therapy for Q fever endocarditis, of doxycycline $100 \mathrm{mg}$ PO BID and hydroxychloroquine $200 \mathrm{mg}$ PO TID.

\section{Discussion}

$\mathrm{Q}$ fever is a zoonotic infection that results from Coxiella burnetti infection. C. burnetti is a pleomorphic rod that is an intracellular bacterium. ${ }^{1}$ The disease was first reported in $1935 \mathrm{after}$ an outbreak at a slaughterhouse in Queensland, Australia: the Q referred to "query" fever. ${ }^{2}$ The organism is typically spread via aerosol transmission from infected animals, and is found worldwide. ${ }^{2} \mathrm{Q}$ fever can present acutely or as a chronic infection. A persistent localized infection such as endocarditis, or bone/joint infection, can develop as a consequence of infection. ${ }^{3}$

\section{Clinical Manifestations}

$\mathrm{Q}$ fever has a wide array of documented presentations in the literature, varying from atypical pneumonia, vascular infections, osteomyelitis, pericarditis, and in four case reports, hemophagocytic syndrome. ${ }^{2,3,5}$ One of the most common presentations is culturenegative endocarditis, which can develop anywhere from 2 weeks to 2 years after acute infection. ${ }^{5}$ In $\mathrm{Q}$ fever endocarditis, extracardiac manifestations are common, including splenomegaly, clubbing and a purpuric rash. ${ }^{5}$ Echocardiography rarely detects vegetative lesions, which are often smooth and nodular in appearance. $^{5}$

\section{Diagnosis}

Diagnosis should be guided by clinical suspicion, taking risk factors for Coxiella exposure and risk factors for developing endocarditis into account. Risk factors for Q fever endocarditis include male sex, age over 40 years, immunocompromized, and underlying valvular damage, including a prosthetic valve. ${ }^{5}$ Risk factors for Coxiella exposure include contact with farm animals; living downwind from a farm; exposure to contaminated manure, straw, or dust; and working with Coxiella in a laboratory setting. ${ }^{5}$

In order to diagnose $\mathrm{Q}$ fever endocarditis, the Duke criteria may be used, with positive $\mathrm{Q}$ fever serology being considered a major clinical criterion. ${ }^{3}$ The principal diagnostic criteria are evidence of endocarditis with confirmation of Coxiella burnetti infection as demonstrated through an IgG titre greater than $800 .^{5}$ Detection of C. burnetti can be done via polymerase chain reaction and does not require viable microorganisms to be accurate. ${ }^{5}$ Culture of C. burnetti can only be performed in a specially equipped laboratory. ${ }^{5}$ 


\section{Treatment and Prognosis}

Q fever endocarditis is treated with combination therapy of doxycycline and hydroxychloroquine for a minimum of 18 months, and in cases of PVE, 24 months. ${ }^{6}$ Treatment may be discontinued after the IgG titre antibodies against phase I antigens decreases by fourfold or more. ${ }^{6}$

\section{Conclusion}

$\mathrm{Q}$ fever endocarditis is a challenging diagnosis that should be considered in patients with culture-negative endocarditis. This is particularly true if there is a history suggestive of possible Coxiella burnetti exposure, such as living on a farm with livestock. Specific serologic testing is available. The Duke criteria can be applied, with positive Coxiella burnetti serology as a major criterion. Treatment depends on whether the infection is acute or chronic, and whether the patient has a native or prosthetic heart valve.

\section{Competing interests: None declared}

\section{References}

1. Stein A, Saunders NA, Taylor AG, Raoult D. Phyogenic homogeneity of Coxiella burnetii stains as determined by $16 \mathrm{~S}$ ribosomal RNA sequencing. FEMS Microbiol Lett 1993;113(3):339-44.

2. Chen $\mathrm{T}$, et al. Acute $\mathrm{Q}$ fever with hemophagocytic syndrome: case report and literature review. Scand J Infect Dis 2006;38(11-12): 1119-22, DOI: $10.1080 / 00365540600684405$.

3. Million M, Raoult D. No such things as chronic Q fever. Emerg Infect Dis 2017;23(5):856-7. doi: hhtps://dx.doi.org/10.3201/eid2305151159

4. Raoult D, Marrie T. Q fever. Clin Infect Dis 1995;20(3):489-95.

5. Fournier PE, Marrie TJ, Raoult D. Diagnosis of Q fever. J Clin Microbiol 1998;36(7):1823-34

6. Million M, Walter G, Thuny F, Habib G, Raoult D. Evolution from acute $Q$ fever to endocarditis is associated with underlying valvulopathy and age and can be prevented by prolonged antibiotic treatment. Clin Infect Dis 2013;57(6):836-44.

\section{Mission Statement}

The CSIM is a non-profit professional society that promotes the health and well being of Canadian patients, their communities, and their health care systems. We seek to foster leadership and excellence in the practice of General Internal Medicine (GIM) through research, education, and advocacy for health promotion and disease management.

\section{Vision}

We believe that General Internal Medicine in Canada plays a central role in the training of current and future clinicians, in clinical research, in patient care, in health promotion, and in health advocacy; and that it unites a body of knowledge, values, and principles of care that lay the foundation for excellence in the Canadian health care system.

\section{Values}

We embrace the ethical and professional standards that are common to all healing professions, as well as the specific values of generalism, teamwork, competency-based training, life-long learning, evidence-based medicine, holism, and humane, patient-centered care.

\section{Mission}

La Société canadienne de médecine interne (SCMI) est une association professionnelle sans but lucratif qui entend promouvoir la santé et le bienêtre des patients, des collectivités et des systèmes de santé canadiens. Elle souhaite également promouvoir le leadership et l'excellence dans l'exercice de la médecine interne générale en favorisant la recherche, léducation, la promotion de la santé et la gestion des soins thérapeutiques.

\section{Vision}

La Société a l'intime conviction que la médecine interne générale occupe une place centrale dans la formation des cliniciens aujourd'hui et à l'avenir, dans la recherche clinique, dans la prestation des soins et des services de santé et dans la promotion de la santé, et que la discipline se fonde sur un savoir, des valeurs et des principes thérapeutiques essentiels à la poursuite de l'excellence dans le système de santé canadien.

\section{Valeurs}

La Société fait sienne les normes éthiques et professionnelles communes aux professions de la santé ainsi que les valeurs particulières du généralisme, du travail déquipe, de la formation axée sur les compétences, de léducation permanente, de la médecine factuelle, de l'holisme et des soins et des services de santé humains, centrés sur le patient.

\section{CSIM Continuing Professional Development Mission Statement}

Our ultimate goal is to go beyond the simple transmission of information. Our goal is to make a lasting impact on the knowledge, skills and attitudes of clinicians and future clinicians; to narrow the theory to practice gap; to improve the health of our patients and of all Canadians.

\section{Mission de la SCMI sur le plan du développement professionnel continu}

Notre but ultime déborde du cadre de la simple transmission d'information. Il consiste à produire un effet durable sur le savoir, les compétences et les attitudes du médecin, à combler lécart qui sépare la théorie de la pratique, à améliorer la santé de nos patients et de tous les canadiens. 